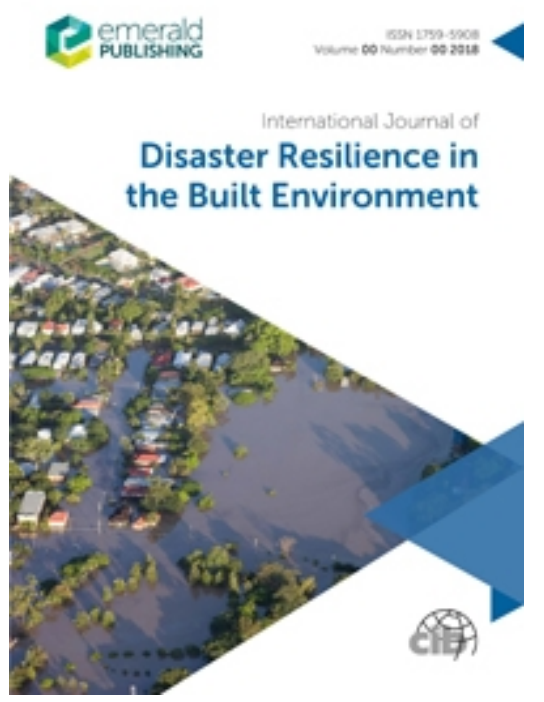

\title{
Cost-based resilience assessment of bridges subjected to earthquakes
}

\begin{tabular}{|r|l|}
\hline Journal: & International Journal of Disaster Resilience in the Built Environment \\
\hline Manuscript ID & Draft \\
\hline Manuscript Type: & Research Paper \\
\hline Keywords: & $\begin{array}{l}\text { Resilience, Earthquakes, Vulnerability, Restoration, Infrastructure, } \\
\text { Disaster mitigation }\end{array}$ \\
\hline \multicolumn{2}{|l}{} \\
\hline
\end{tabular}

\section{SCHOLARONE \\ Manuscripts}




\section{Cost-based resilience assessment of bridges subjected to earthquakes}

\section{ABSTRACT}

4 Transport infrastructure resilience is of paramount importance for societies and economies, therefore its quantification

\section{Introduction}

Bridges are key assets of the transport infrastructure, upon which world economies and societies heavily rely. Recent natural disasters have revealed the vulnerabilities of bridge infrastructure to diverse hazards, e.g. earthquakes, liquefaction, floods or tsunami, and they had led to significant economic losses and longterm disruptions to the transport network. For example, during the 2009 floods in Cumbria, UK, at least 20 bridges were destroyed or damaged, causing one fatality, $£ 34 \mathrm{~m}$ of restoration costs and large societal impact (Cumbria County Council, 2010). The impact of seismic ground motion and cascading hazards such as liquefaction, landslides or tsunamis on bridges and transport networks has been also tremendous in past events across the world (Akiyama et al., 2019; Nakanishi et al. 2014). Therefore, assessing the vulnerabilities and quantifying the resilience of bridges and transport networks exposed to natural hazards and in particular, earthquakes and floods, is of paramount importance for the safety and continuity of services, and hence for the growth of economy and the resilience of communities (Rehak et al. 2019; Komendantova et al. 2016). Resilience describes the emergent property or attributes that a bridge or a network has, which allows them to withstand, respond and/or adapt to a vast range of disruptive events by preserving and even enhancing critical functionality (Ayyub, 2014, Elms et al. 2019). Resilience accounts for structural functionality and recovery planning after the occurrence of a hazard, to achieve downtime objectives as defined by the owners or network operators. Metrics of resilience usually measure the quality components and the rapidity of damage restoration. Hence, owners and operators would be benefited in the decisionmaking process from quantifications of resilience that account for different hazard events, the type and extent of expected damage, the direct and indirect losses and the time of restoration. This paper presents a resilience assessment framework based on well-informed resilience indices, taking into account the abovementioned factors. The framework application quantifies the robustness of bridges against different seismic hazard scenarios, by utilizing realistic fragility functions and the rapidity of the recovery and/or retrofitting after the occurrence of a certain degree of damage, based on realistic restoration functions. Two different approaches for the modelling of the restoration tasks are examined. Both direct losses due to structural damage and indirect losses due to traffic disruption are included in and more resilient infrastructure.

Keywords: bridges, resilience, earthquakes, vulnerability, restoration, direct and indirect losses, transport networks 
38 or performance of the asset or system before and after the event (Hosseini et al., 2016), considering the robustness, redundancy, resourcefulness and rapidity to recovery (Bruneau et al., 2013). In this context, resilience-based design and management are the new principles that are gradually being adopted in practical applications of critical infrastructure and are expected to be incorporated in the next generation of codes, as for example the Resilience-based Earthquake Design Initiative (REDi) for the Next Generation of Buildings (Almufti \& Willford, 2013). Risk and resilience assessment frameworks have been proposed for bridges subjected to single hazards (Decò et al., 2013, Bocchini \& Frangopol, 2012a) and multiple hazards (Bocchini et al., 2012, Dong \& Frangopol 2015, Argyroudis et al., 2020, Banerjee et al., 2019) and for transport networks (Bocchini \& Frangopol, 2012b, Zhang et al., 2017, Twumasi-Boakye \& Sobanjo, 2018).

The resilience assessment frameworks include the characterization of hazard, the vulnerability of the assets and the evaluation of consequences in terms of functionality and repair loss. In some cases, the indirect losses due to traffic disruptions are also accounted in the assessment (Decò et al., 2013, Dong \& Frangopol 2015, Banerjee et al., 2019). The vulnerability of a bridge under a given hazard can be obtained using fragility functions, which describe the probability of the structure experiencing or exceeding a damage state, for a given intensity measure, e.g. peak ground acceleration (PGA). Available fragility functions for bridges and other transport infrastructure are summarised by Argyroudis et al. (2019), Billah \& Alam (2015) and Gidaris et al. (2017). Fragility functions can be derived based on analytical (e.g. Moschonas et al., 2009), empirical (e.g. Basoz et al., 1999; Elnashai et al., 2004) or hybrid approaches for classes of bridges or specific bridges accounting for the effect of geometry, structural system, component and soil properties (Stefanidou \& Kappos, 2018). Fragility functions are essential for the estimation of direct, i.e. due to bridge repair, and indirect, i.e. due to loss of bridge functionality, losses. The functionality of the damaged bridge is commonly defined based on engineering judgement (Mackie \& Stojadinovic, 2006; FEMA, 2009; restoration functions, which are necessary for the quantification of resilience and the estimation of the direct and indirect losses. The restoration functions express the rapidity of recovery and they can be expressed by different shapes, such as linear (Chandrasekaran \& Banerjee 2016), trigonometric (Cimellaro et al., 2010; Bocchini \& Frangopol, 2012a), step-wise (Padgett \& DesRoches, 2007; Sharma et al., 2018) or cumulative distribution functions (FEMA, 2009; Bocchini et al., 2012). The restoration process depends on the type of asset, the damage level, the availability of resources and the prioritization of the owner's goals (Hayat et al. 2019).

The novelty of this paper is the delivery of well-thought restoration functions for three very common highway bridges, for which alternative approaches for expressing the restoration strategies were examined and assessed with regard to their practicality. In this context, a typical risk and resilience assessment framework is employed to these representative bridges, which lie along the Ring Road of Thessaloniki, Greece, considering exposure and damages to earthquake hazards. The vulnerability of the bridges against different seismic scenarios is quantified by utilizing realistic fragility functions and the rapidity of the 
recovery after the occurrence of a certain degree of damage is estimated based on realistic restoration

functions. The restoration process is modelled accounting for realistic and representative restoration tasks of the damaged bridge components, considering the post-disaster idle time and the repair duration variability. Two different restoration models are examined: a linear (deterministic) as per FEMA (2009) and a cumulative normal distribution one (stochastic) on the basis of a Monte-Carlo simulation (Sgambi et al., 2014). The resilience assessment is based on a well-informed resilience index, which is a function of the time-variant functionality of the infrastructure over the restoration time for these scenarios. The resilience assessment is inclusive of direct and indirect losses for the given seismic scenarios. In this context a new cost-based resilience index is also introduced, accounting for the effect of indirect losses in the resilience of the assets. The scope of this study is to demonstrate the applicability of the resilience assessment framework and to highlight the role of the restoration models, which can be adapted to the construction practices that are typically implemented in the region where the bridge is located, the policies of the stakeholders, e.g. time required to commence the restoration, and the capabilities of the contractors, or the availability of different types of resources, e.g. funds, materials, equipment, human resources. The results of this research are expected to facilitate owners to enhance decision-making and risk management on the basis of cost-based and well-informed indices toward more resilient infrastructure.

\section{Resilience assessment framework}

Resilience assessment requires the accurate evaluation of the asset damage for given hazard intensities and the realistic simulation of the restoration strategies of the studied system, e.g. transportation network, and its assets, e.g. bridges. Resilience is typically correlated with the evolution of asset functionality during the recovery process, therefore a time-dependent analysis is enabled in the assessment. Figure 1 illustrates the framework that is adopted herein, which encompasses hazard, vulnerability, loss and resilience analysis and is applied for representative bridges exposed to earthquakes. In particular, seismic hazard analysis defines the hazard Intensity Measures (IM) at the bridge site, based on available hazard models such as the 2013 European Seismic Hazard Model - ESHM13 (Woessner et al., 2015), which provides seismic hazard data on rock conditions. The local site effects on the seismic ground motion can be accounted through simplified, yet, rigorous approaches, such as the use of soil amplification factors depending on the soil type (Pitilakis et al., 2013).

The vulnerability, which expresses the robustness of the structure, i.e. the ability of the structure to withstand seismic loads, is evaluated on the basis of fragility functions for specific typologies of bridges (Argyroudis et al., 2019). Fragility functions provide the probability of being or exceeding specific Damage States (DSi) for given IMs, i.e. intact (DS0), slight damage (DS1), moderate damage (DS2), extensive damage (DS3) and failure/collapse (DS4) as per Equation 1.

$$
\text { Fragility }=\mathrm{P}\left[\mathrm{ds}>\mathrm{DS}_{\mathrm{i}} \mid \mathrm{IM}\right], \mathrm{i}=0, \ldots, 4
$$


where $C$ is the replacement cost of the bridge per square meter, $W$ and $L$ are the width and the length of the bridge and $P\left[D S_{i} \mid I M\right]$ is the probability of occurrence of each DS for an event with a given $I M$ :

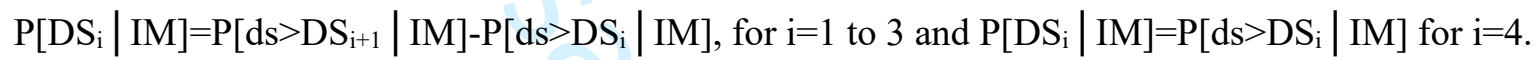
The $D R$ quantifies the repair cost as a ratio of the replacement cost of the bridge. FEMA (2009) suggests the following DR for each DSi: $\mathrm{DR}_{0}=0, \mathrm{DR}_{1}=0.03, \mathrm{DR}_{2}=0.08, \mathrm{DR}_{3}=0.25$ and $\mathrm{DR}_{4}=1$, if $\mathrm{n}<3$ or $=2 / \mathrm{n}$, if $\mathrm{n}>=3$, where $\mathrm{n}$ is the number of spans. For example, extensive damage state (DS3) means that the damage corresponds to a repair cost of about $25 \%$ of the replacement cost of the bridge. In some cases, the cost for removal of debris and construction of a temporary bypass is included in the estimation of $C_{D}$ (Decò et al., 2013).

The indirect cost $\left(\mathbf{C}_{\mathbf{I N}}\right)$ due to loss of the bridge's functionality, is commonly calculated accounting for the additional costs due to the detour of the traffic. According to Dong \& Frangopol (2015) the indirect cost associated with a detour on a bridge can be evaluated as the summation of the operating cost of vehicles on detour $\left(C_{o p}\right)$ and the cost due to vehicle time loss $\left(C_{T L}\right)$ caused by the bridge damage. The $C_{o p}$ and $C_{T L}$ can be expressed as in Equation 3 and 4 respectively, modified by the authors to consider a linear reduction of the daily traffic on detour as the repair works of the damaged bridge proceed.

$$
\mathrm{C}_{\mathrm{op}}=\sum_{\mathrm{i}=1}^{4}\left\{\mathrm{P}\left[\mathrm{ds}=\mathrm{DS}_{\mathrm{i}} \mid \mathrm{IM}\right]\left(\mathrm{T}_{\text {idl, }}+\frac{1}{2} \mathrm{~T}_{\text {res, },}\right)\left[\mathrm{C}_{\mathrm{op}, \mathrm{car}}\left(1-\frac{\mathrm{TR}_{\mathrm{D}}}{100}\right)+\mathrm{C}_{\mathrm{op}, \text { truck }} \frac{\mathrm{TR}_{\mathrm{D}}}{100}\right] \mathrm{D}_{\mathrm{l}} \mathrm{ADT}\right\}
$$

where $T_{i d l, i}$ and $T_{r e s, i}$ are the idle and restoration time, respectively, of a damaged bridge at each DS, $C_{o p, c a r}$ and $C_{o p, t r u c k}$ are the average costs of operation of car and truck per kilometer length $(\$ / \mathrm{km})$, respectively, $D_{l}$ is the detour length $(\mathrm{km}), A D T$ is the average daily traffic on detour, calculated as 1 minus the average functionality (i.e. weighted with the probabilities of occurrence of each DS) of the examined bridge, multiplied by its average total daily traffic, and $T R_{D}$ is the average daily truck traffic ratio (\%). It is noted that in the present study, Equation 3 was modified by replacing the $D_{l}$ factor with $D_{l} l$, representing the additional route length, where $l$ is the length of the link $(\mathrm{km})$, which would had been traveled by the drivers 
where the terms $C_{A W}, C_{A T C}$ and $C_{\text {goods }}$ correspond to the average wage per hour (\$/h), the average total compensation per hour $(\$ / h)$ and the monetary value of time taken to transport goods in cargo $(\$ / h)$, respectively, $O_{\text {car }}$ and $O_{\text {truck }}$ are the average vehicle occupancies for car and truck, respectively, $S$ is the average velocity on detour $(\mathrm{km} / \mathrm{h}), S_{D}$ and $S_{0}$ are the average velocities $(\mathrm{km} / \mathrm{h})$ on the damaged and intact bridge, respectively, and $A D E$ is the average daily traffic remaining on the bridge after the seismic event, calculated by the average functionality of the bridge (i.e. weighted with the probabilities of occurrence of each DS) multiplied by its average total daily traffic. Obviously, the summation of ADT and ADE is equal to the total average traffic.

The resilience curve of a bridge subjected to a certain ground shaking level can be generated based on the restoration functions, which describe the rapidity of functionality recovery for the different DSs, and the probabilities of occurrence of each DS.

$$
\mathrm{Q}(\mathrm{t})=\sum_{\mathrm{i}=0}^{4} \mathrm{Q}\left[\mathrm{DS}_{\mathrm{i}} \mid \mathrm{t}\right] \mathrm{P}\left[\mathrm{DS}_{\mathrm{i}} \mid \mathrm{IM}\right]
$$

where $Q[D S i \mid t]$ is the functionality of the bridge being in DSi, at time $t$ after the commencement of the restoration, as it is given by the restoration functions.

The Resilience index $(\mathrm{R})$ of a bridge can be calculated from the resilience curves and represents the area under the resilience curve. An efficient way of estimating the resilience index is proposed by Decò et al., (2013), as it is shown in Equation 6.

$$
\mathrm{R}=\frac{1}{\mathrm{t}_{\mathrm{h}}-\mathrm{t}_{\mathrm{o}}} \int_{\mathrm{t}_{\mathrm{o}}}^{\mathrm{t}_{\mathrm{h}}} \mathrm{Q}(\mathrm{t})
$$

where $t_{o}$ is the time of an earthquake occurrence, $t_{h}$ is the time horizon, such as the time instance where the bridge has been fully recovered (including the idle and repair time), $t$ is the time variable and $Q(t)$ is the 
180 The resilience assessment framework of the abovementioned calculation procedure is shown in Figure 1.

bridge functionality at time $t$. The resilience index that accounts for the indirect costs is described in Section 4.

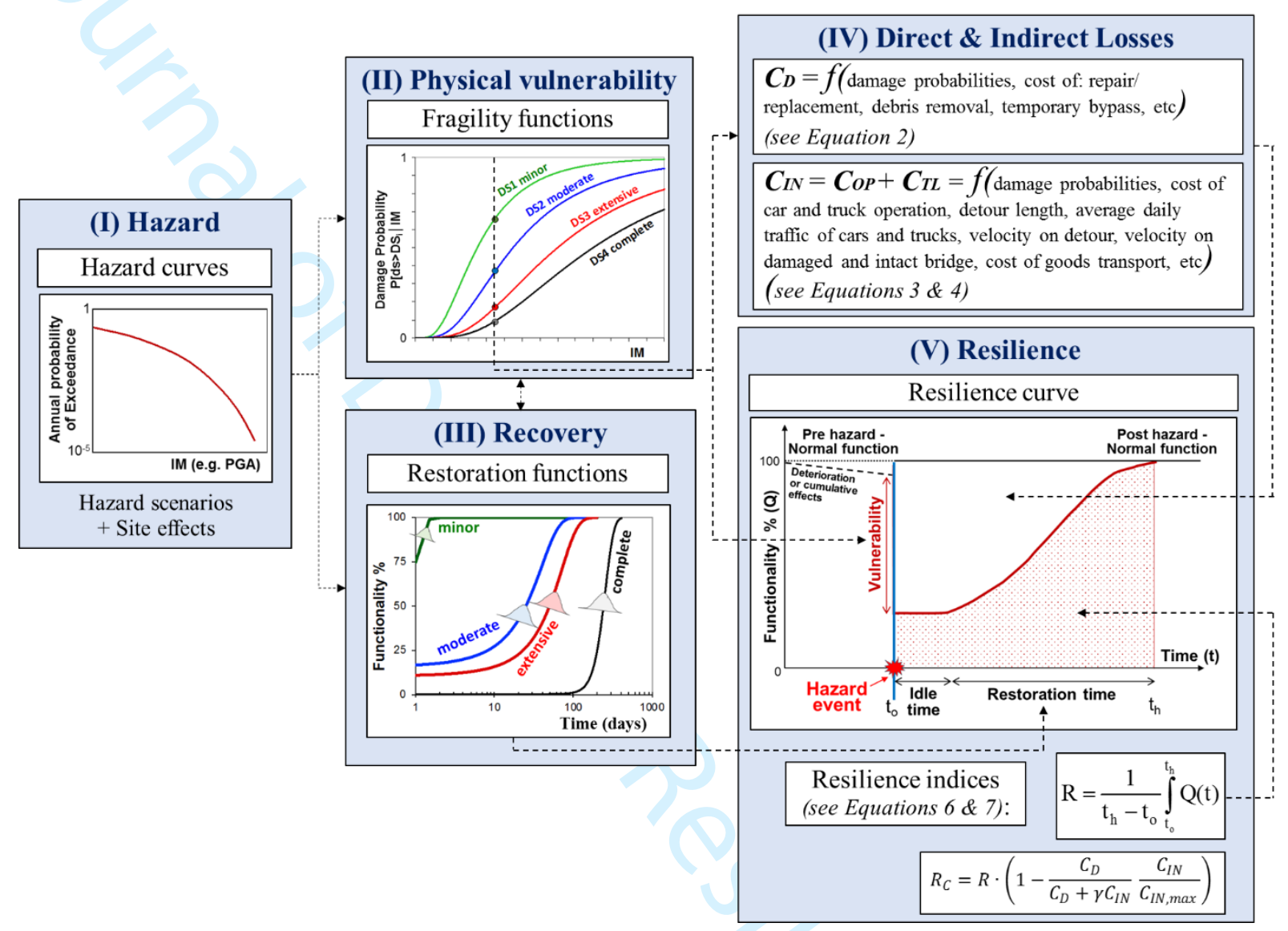

Figure 1. Framework for resilience assessment

\section{Application to a portfolio of bridges}

\subsection{Description of bridges}

The three analyzed bridges of this study are given in Table 1 . The bridges are classified according to Moschonas et al., (2009) based on three critical typology parameters, which are: (1) type of piers, (2) type of deck and (3) type(s) of pier-to-deck connections. In the following, these three bridges are named after "Bridge 1", "Bridge 2" and "Bridge 3". Bridge 1 is located at Neapoli's Valley and it was built in 1984. It is a three-span bridge of total length $120 \mathrm{~m}$, having simply-supported precast and prestressed beams connected through a continuous reinforced concrete slab that is supported through bearings on multicolumn bents with surface foundations. Bridge 2 is located at interchange K12 along the Ring Road and it was built in 1992. It has three-spans and a total length of $77 \mathrm{~m}$, having a cast-in-situ box-girder (triple cell) deck supported through bearings on wall-type piers with pile foundations. Bridge 3 is located at interchange K8 and was constructed in 2002. It is a seven-span bridge with a total length of $147 \mathrm{~m}$ and has a box-girder (single-cell) deck, which is either rigidly connected to the single-column hollow rectangular piers or seating upon them through bearings. The piers are founded on superficial foundations. For all the bridges described above the abutments are typical seat-type abutments with expansion joints and bearings. Thus, Bridge 1, 
198 Bridge 2 and Bridge 3 correspond to types 332, 422 and 223, respectively, according to the Moschonas et 199 al., (2009) classification. Bridges 1 and 3 are located on a rock formation (ground type A), while Bridge 2 200 is founded on very dense sand to clay soil formation (ground type B2, according to the classification 201 proposed by Pitilakis et al., 2013).

Table 1. Portfolio of bridges along the ring-road of Thessaloniki

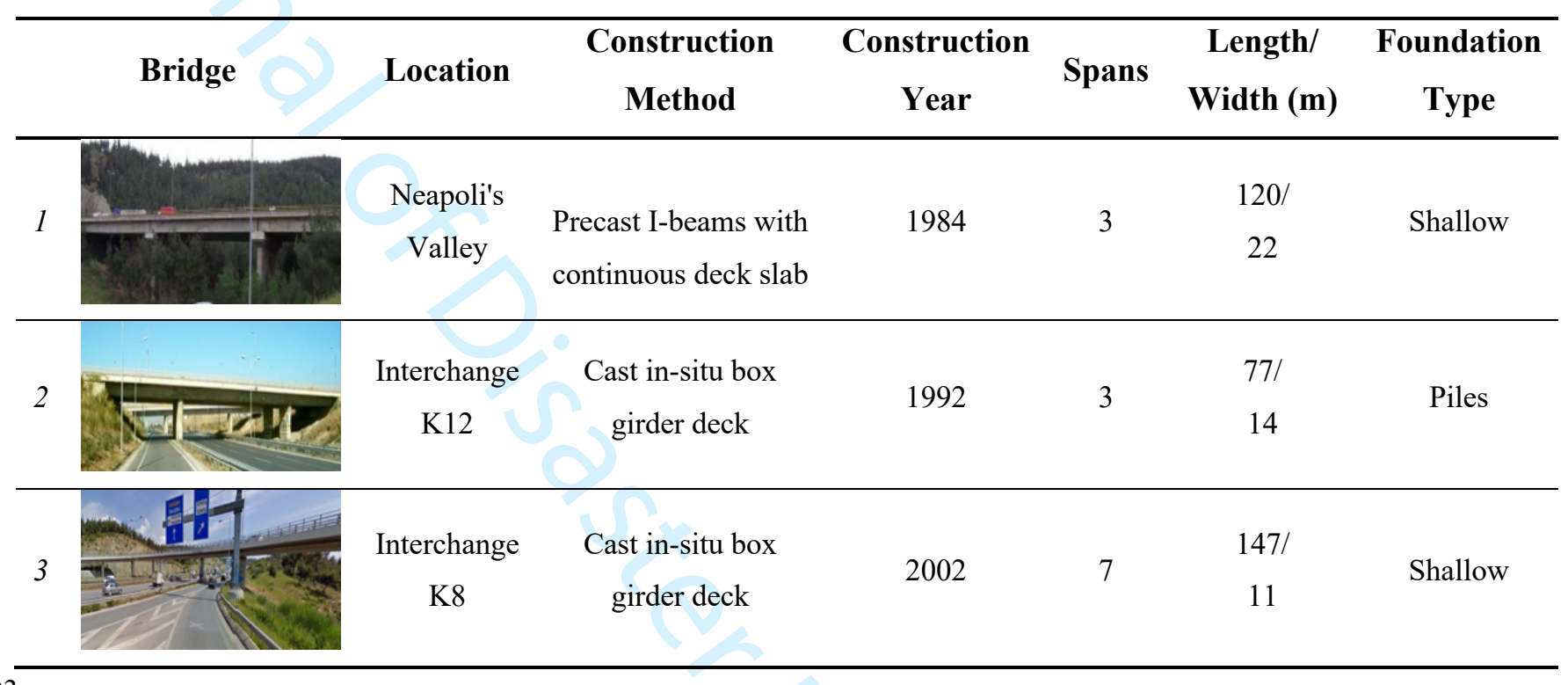

203 30

\subsection{Seismic hazard}

The three bridges of this case study are analyzed for two seismic scenarios. The first one refers to an earthquake with a probability of exceedance equal to $10 \%$ in 50 years (Scenario I) corresponding to a return period of 475 years and the second with probability $5 \%$ in 50 years (Scenario II) corresponding to a return period of 975 years. The intensity measure that has been chosen is the PGA, which is obtained on rock conditions for each bridge location, using the hazard curves provided by the ESHM13 (Woessner et al., 2015). To account for the local soil conditions the obtained $\mathrm{PGA}_{\text {rock }}$ values are multiplied by an amplification soil factor, $\mathrm{S}_{\text {soil }}$, (Pitilakis et al, 2013, for Ms $>5.5$ ). The estimated PGA values are shown in Table 2 and they are used to calculate the exceedance and occurrence probabilities of specific DS based on the selected fragility curves.

Table 2. PGA values at the site of the three bridges

\begin{tabular}{|c|c|c|c|c|}
\hline Bridge & $\mathbf{S}_{\text {soil }}$ & Scenario & PGA $_{\text {rock }}(\mathrm{g})$ & PGA (g) \\
\hline \multirow{2}{*}{1} & \multirow{2}{*}{1.0} & I & 0.26 & 0.26 \\
\hline & & II & 0.38 & 0.38 \\
\hline \multirow{2}{*}{2} & \multirow{2}{*}{1.3} & I & 0.26 & 0.34 \\
\hline & & II & 0.38 & 0.49 \\
\hline \multirow{2}{*}{3} & \multirow{2}{*}{1.0} & I & 0.28 & 0.28 \\
\hline & & II & 0.40 & 0.40 \\
\hline
\end{tabular}




\subsection{Vulnerability analysis}

219 The fragility functions used for the vulnerability assessment are based on the study of Moschonas et al., 220 (2009) for bridges constructed with the latest seismic provisions, i.e. after 1993. The fragility functions were developed based on numerical modelling, using damage criteria defined by the yielding and the ultimate displacements of the bridge and the abutment-backfill system as well as the expansion joint width (gap). For the needs of this study, the response of the bridge in the longitudinal direction is considered only, taking into account the abutment-backfill interaction including gap closure. It is also recognized that bridges designed without advanced provisions exhibit greater vulnerabilities than the once designed based on guidelines on earthquake resistance. Due to the absence of available and compatible fragility functions, for taking into account the reduced capacity of bridges designed prior to 1993 , a factor, $\mathrm{S}_{\text {year }}$, is introduced that increases the median threshold values of the intensity measure $\left(\mathrm{PGA}_{i m}\right)$ required for causing the DSi. This factor was chosen based on expert judgment and was reflected by reducing the capacity per decade of construction prior to 1993 , as follows: $2.5 \%$ for DS1, $5 \%$ for DS2, $7.5 \%$ for DS3 and $10 \%$ for DS4. The reduction was considered as different at each DS, because a bridge constructed before 1993 is expected to be less resilient for larger-scale damages. As an exception, for Bridge 2, which was constructed in 1992, $\mathrm{S}_{\text {year }}$ was chosen equal to 1.0 for DS1 and DS2, 0.025 for DS3 and 0.05 for DS4. For Bridge 3, the median values were unchanged and equal to 0.09 for DS1, 0.20 for DS2, 0.32 for DS3 and 0.48 for DS4. The modified fragility parameters are shown in Table 3 and the fragility curves, which follow a lognormal cumulative distribution function, are illustrated in Figure 2. It is noted that the total lognormal standard deviation is constant for all DSs and was not modified, i.e. $\beta_{\text {tot }}=0.6$. The calculated damage probabilities for the two seismic scenarios are shown in Table 4.

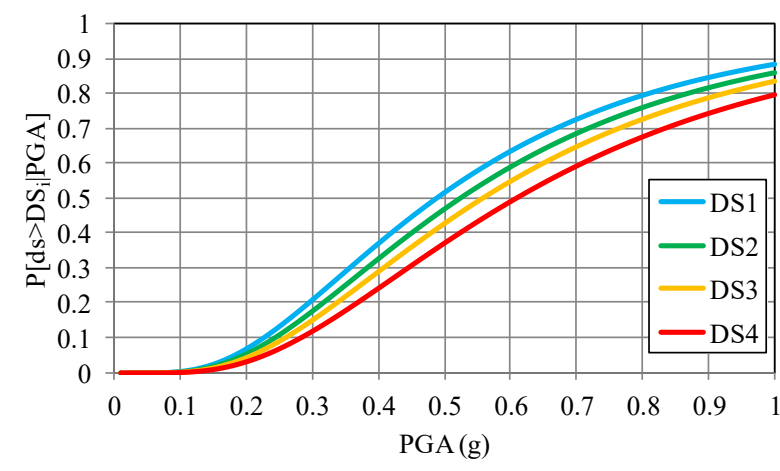

(a)

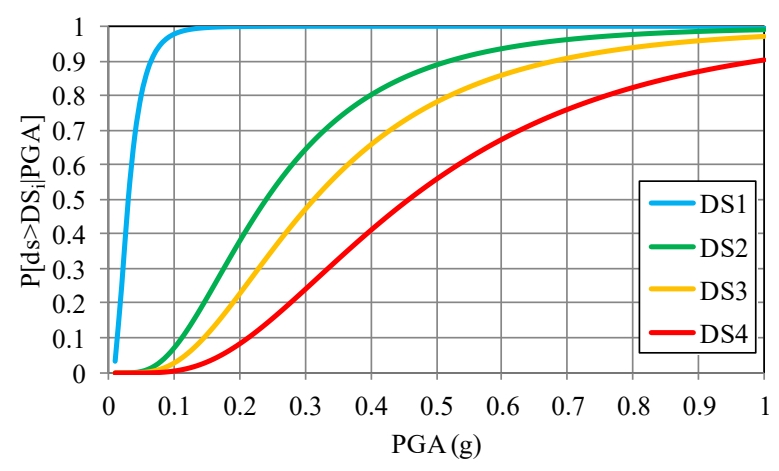

(b) 


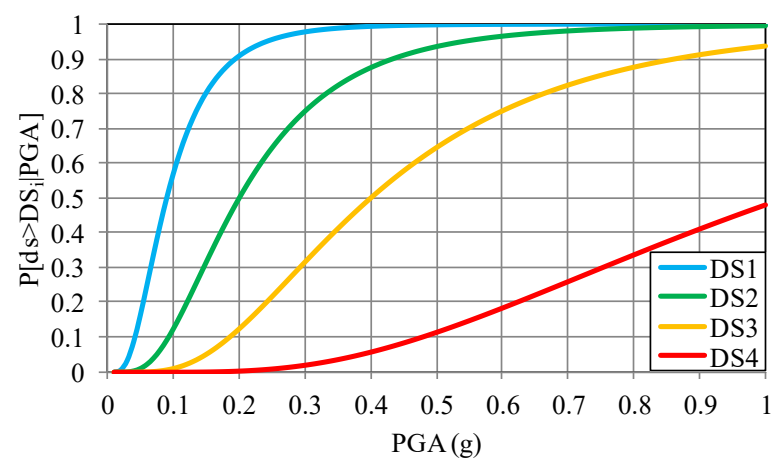

(c)

Figure 2. Fragility curves for PGA at the soil surface for: (a) Bridge 1, (b) Bridge 2 and (c) Bridge 3

Table 3. Fragility parameters for the Bridges 1 and 2

\begin{tabular}{|c|c|c|c|c|c|}
\hline Bridge & Construction year & DS & $\mathbf{S}_{\text {year }}$ & PGA $_{\text {im }}(\mathrm{g})$ & $\mathrm{PGA}_{\text {im (reduced) }}(\mathrm{g})$ \\
\hline \multirow{4}{*}{1} & \multirow{4}{*}{1984} & 1 & 0.976 & 0.50 & 0.49 \\
\hline & & 2 & 0.952 & 0.55 & 0.52 \\
\hline & & & 0.930 & 0.60 & 0.56 \\
\hline & & 4 & 0.909 & 0.67 & 0.61 \\
\hline \multirow{4}{*}{2} & \multirow{4}{*}{1992} & 1 & 1.000 & 0.03 & 0.03 \\
\hline & & 2 & 1.000 & 0.24 & 0.24 \\
\hline & & 3 & 0.976 & 0.32 & 0.31 \\
\hline & & 4 & 0.952 & 0.48 & 0.46 \\
\hline
\end{tabular}


Table 4. Probabilities of exceedance and occurrence of each DS for the three bridges subject to two seismic scenarios

\begin{tabular}{|c|c|c|c|c|}
\hline \multicolumn{5}{|c|}{ Bridge 1} \\
\hline 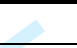 & \multicolumn{2}{|c|}{ Seismic Scenario I } & \multicolumn{2}{|c|}{ Seismic Scenario II } \\
\hline DS & $P\left[d s>D_{i} \mid\right.$ PGA $]$ & $\mathbf{P}\left[\mathrm{DS}_{\mathbf{i}} \mid \mathbf{P G A}\right]$ & $P\left[d s>D S_{i} \mid P G A\right]$ & $\mathbf{P}\left[\mathrm{DS}_{\mathrm{i}} \mid \mathbf{P G A}\right]$ \\
\hline 0 & 1.00 & 0.85 & 1.00 & 0.66 \\
\hline 1 & 0.15 & 0.03 & 0.34 & 0.04 \\
\hline 2 & 0.12 & 0.02 & 0.30 & 0.04 \\
\hline 3 & 0.10 & 0.02 & 0.26 & 0.04 \\
\hline 4 & 0.08 & 0.08 & 0.22 & 0.22 \\
\hline \multicolumn{5}{|c|}{ Bridge 2} \\
\hline & \multicolumn{2}{|c|}{ Seismic Scenario I } & \multicolumn{2}{|c|}{ Seismic Scenario II } \\
\hline DS & $P\left[d s>D_{i} \mid\right.$ PGA $]$ & $\mathbf{P}\left[\mathrm{DS}_{\mathrm{i}} \mid \mathbf{P G A}\right]$ & $P\left[d s>D_{i} \mid\right.$ PGA $]$ & P[DS $\mathbf{S}_{\mathrm{i}} \mid$ PGA $]$ \\
\hline 0 & 1.00 & 0.01 & 1.00 & 0.01 \\
\hline 1 & 0.99 & 0.27 & 0.99 & 0.11 \\
\hline 2 & 0.72 & 0.16 & 0.88 & 0.11 \\
\hline 3 & 0.56 & 0.25 & 0.77 & 0.23 \\
\hline 4 & 0.31 & 0.31 & 0.55 & 0.55 \\
\hline \multicolumn{5}{|c|}{ Bridge 3} \\
\hline & \multicolumn{2}{|c|}{ Seismic Scenario I } & \multicolumn{2}{|c|}{ Seismic Scenario II } \\
\hline DS & $\mathbf{P}\left[\mathbf{d s}>\mathrm{DS}_{\mathrm{i}} \mid \mathbf{P G A}\right]$ & $\mathbf{P}\left[\mathrm{DS}_{\mathrm{i}} \mid \mathbf{P G A}\right]$ & $\mathbf{P}\left[\mathbf{d s}>\mathrm{DS}_{\mathrm{i}} \mid \mathbf{P G A}\right]$ & $\mathbf{P}\left[D_{S_{i}} \mid\right.$ PGA $]$ \\
\hline 0 & 1.00 & 0.03 & 1.00 & 0.01 \\
\hline 1 & 0.97 & 0.26 & 0.99 & 0.12 \\
\hline 2 & 0.71 & 0.44 & 0.88 & 0.38 \\
\hline 3 & 0.28 & 0.26 & 0.50 & 0.44 \\
\hline 4 & 0.02 & 0.02 & 0.06 & 0.06 \\
\hline
\end{tabular}

\subsection{Direct and indirect costs}

The direct costs $\left(C_{D}\right)$ of the examined bridges are evaluated according to Equation 2 and the probabilities of Table 4, using typical construction costs of bridges in Greece. These costs depend mainly on the construction method and their complexity and they were estimated as $C_{1}=1500 \$ / \mathrm{m}^{2}$ for Bridge $1, C_{2}=1800$ $\$ / \mathrm{m}^{2}$ for Bridge 2 and $\mathrm{C}_{3}=2000 \$ / \mathrm{m}^{2}$ for Bridge 3. The DRs of each DS have been considered as $\mathrm{DR}_{0}=0$, $\mathrm{DR}_{1}=0.03, \mathrm{DR}_{2}=0.08, \mathrm{DR}_{3}=0.25$ and $\mathrm{DR}_{4}=0.75 . \mathrm{DR}_{0} \sim \mathrm{DR}_{3}$ as per Werner et al., (2006), while $\mathrm{DR}_{4}$ has been modified by the authors to 0.75 , in order to represent the multi-span bridge failure or collapse conditions.

For the estimation of the indirect losses $\left(C_{I N}\right)$ due to traffic deviations, an alternative detour is proposed for each one of the examined bridges, as shown in Figure 3. The indirect cost is estimated based on Equations 3 and 4 , and the values of the relevant parameters were defined based on available data, expert judgment and evidence in available literature (Venkittaraman \& Banerjee, 2014). In particular, $\mathrm{C}_{\mathrm{op}, \mathrm{car}}$ was considered 

equal to 0.20 and $C_{\text {op,truck }}$ equal to $0.30 \$ / \mathrm{km}, \mathrm{TR}_{\mathrm{D}}=20 \%$, both $\mathrm{C}_{\mathrm{AW}}$ and $\mathrm{C}_{\mathrm{ATC}}$ were taken equal to $7 \$ / \mathrm{h}, \mathrm{O}_{\text {car }}$ $=2.0$ and $\mathrm{O}_{\text {truck }}=2.0, \mathrm{C}_{\text {goods }}=3 \$ / \mathrm{h}, \mathrm{S}_{\mathrm{D}}=50 \mathrm{~km} / \mathrm{h}, \mathrm{S}_{0}=90 \mathrm{~km} / \mathrm{h}$ and $\mathrm{S}=40 \mathrm{~km} / \mathrm{h}$. The ADE and ADT were considered as fractions of the average daily traffic, which was set equal to 50,000 vehicles per day based on the local traffic conditions. Specifically, ADE was considered equal to the remained functionality of the bridge at each DS multiplied by the average daily traffic (i.e. 50,000 vehicles per day), while ADT is equal to the difference between the average daily traffic and the ADE at each DS. The post-event functionality at each DS was defined as $75 \%$ for DS1, 25\% for DS $2,10 \%$ for DS3 and $0 \%$ for DS4, as per FEMA (2009). The low functionality in extensive damage corresponds to emergency mobility. It is noted that the functionality of a bridge at each DS is considered as the percentage of the bridge capacity to sustain loads and is proportional to the ability of the bridge to carry traffic. This means that a bridge with functionality equal to $50 \%$ can bear only half of the normal traffic loads. However, this is an assumption that might be adapted according to case-specific conditions and requirements of the stakeholders or contractors, for example, traffic can be completely prohibited until bridge repair is completed.

The estimated costs (direct, indirect, and total) for the three bridges are shown in Table 5 for the two earthquake scenarios. The indirect losses' increment as a function of time is shown in Figure 4. It is observed that the higher the seismic intensity the higher the repair costs, because the IMs, and hence the damage probabilities, are higher. Although Bridge 3 has the largest area and repair cost per square meter from the three bridges examined, the highest costs are estimated for Bridge 2 for both scenarios. This is due to the higher vulnerability of Bridge 2 and the relatively long detour length. Also, Bridge 2, has the highest $\mathrm{C}_{\mathrm{D}} / \mathrm{C}_{\mathrm{IN}}$ ratio, as the indirect losses are expected to be about 25 times more than the direct losses for Scenario II. The lowest $C_{D} / C_{I N}$ ratio was estimated for Bridge 1 , i.e. about 4 for both scenarios. The estimated ratios are in good agreement with past studies on highway bridges, which have considered the indirect losses 5 to 20 times greater than the direct losses (Venkittaraman \& Banerjee 2014).

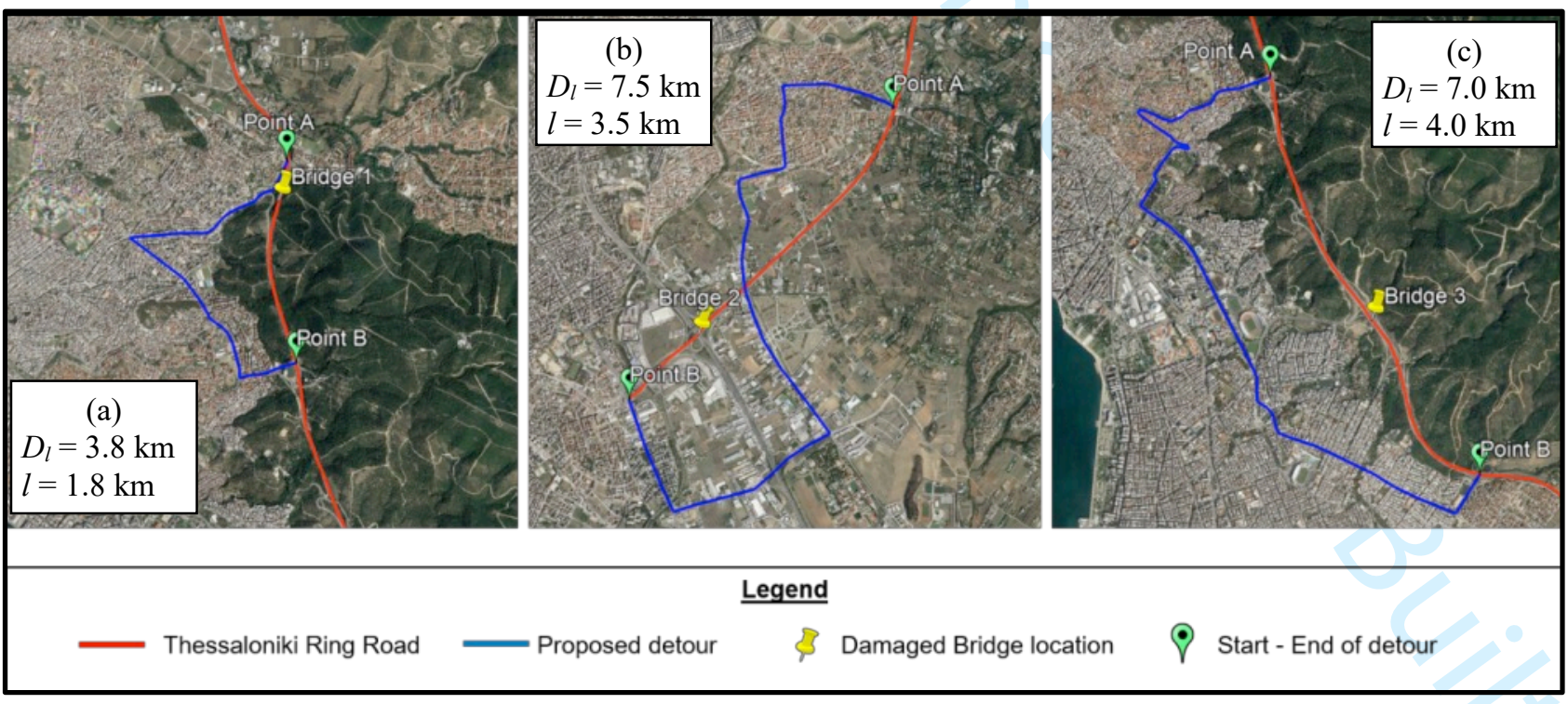

Figure 3. Alternative detours for (a) Bridge 1, (b) Bridge 2 and (c) Bridge 3. $D_{l}$ is the detour length (blue line) and $l$ is the length of the link (distance from point A to $\mathrm{B}$ on the red line). 
Table 5. Direct (repair) and indirect costs of the Thessaloniki's Ring Road examined bridges

\begin{tabular}{ccccccccc}
\hline \multirow{2}{*}{ Bridge } & \multicolumn{4}{c}{ Scenario I } & \multicolumn{5}{c}{ Scenario II } \\
\cline { 2 - 9 } & $\begin{array}{c}\text { Direct } \\
\left(\mathrm{C}_{\mathrm{D}}\right)\end{array}$ & $\begin{array}{c}\text { Indirect } \\
\left(\mathrm{C}_{\mathrm{IN}}\right)\end{array}$ & $\begin{array}{c}\text { Total } \\
\left(\mathrm{C}_{\mathrm{TOT}}\right)\end{array}$ & $\begin{array}{c}\text { Ratio } \\
\left(\mathrm{C}_{\mathrm{IN}} / \mathrm{C}_{\mathrm{D}}\right)\end{array}$ & $\begin{array}{c}\text { Direct } \\
\left(\mathrm{C}_{\mathrm{D}}\right)\end{array}$ & $\begin{array}{c}\text { Indirect } \\
\left(\mathrm{C}_{\mathrm{IN}}\right)\end{array}$ & $\begin{array}{c}\text { Total } \\
\left(\mathrm{C}_{\mathrm{TOT}}\right)\end{array}$ & $\begin{array}{c}\text { Ratio } \\
\left(\mathrm{C}_{\mathrm{IN}} / \mathrm{C}_{\mathrm{D}}\right)\end{array}$ \\
\hline 1 & $\$ 264,651$ & $\$ 545,416$ & $\$ 810,067$ & 2.1 & $\$ 702,279$ & $\$ 2,116,326$ & $\$ 2,818,605$ & 3.0 \\
\hline 2 & $\$ 612,670$ & $\$ 13,137,513$ & $\$ 13,750,183$ & 21.4 & $\$ 928,214$ & $\$ 22,368,967$ & $\$ 23,297,181$ & 24.1 \\
\hline 3 & $\$ 385,525$ & $\$ 4,444,235$ & $\$ 4,829,760$ & 11.5 & $\$ 606,013$ & $\$ 7,145,407$ & $\$ 7,751,420$ & 11.8 \\
\hline 287 & & & & & & & &
\end{tabular}

287

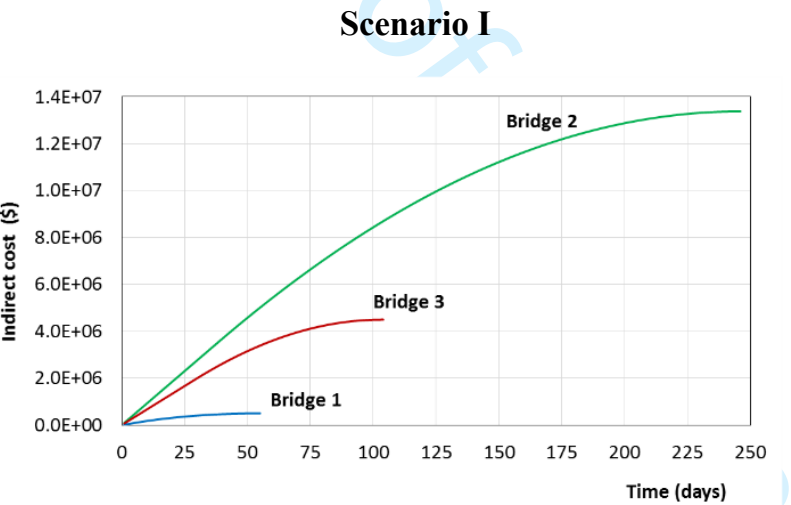

\section{Scenario II}

Figure 4. Cumulative indirect loss for the three bridges and the two seismic scenarios

\subsection{Resilience analysis}

The repair time for each DS and bridge has been estimated by selecting realistic repair works from Karamlou \& Bocchini (2017), as it is shown in Table 6. The selection was made on the basis of the bridge characteristics typology and geometry and the definition of the DSs. The duration of the repair tasks in the present application was adjusted based on engineering judgement considering realistic local construction practices. For example, the increased time for realignment or replacement of bearings in Bridge 1, is due to the large number of bearings and the limited access to the pier caps due to the height of the bridge. Additionally, no damage is expected on the piers of Bridge 1 as they are fully isolated with bearings, whereas in Bridge 3 there are piers rigidly connected to the deck and hence damage is expected. Furthermore, it is assumed that the repair tasks are subsequent, i.e. in series. Since the duration of the repair tasks is described by Karamlou \& Bocchini (2017) using a triangular or uniform probability distribution, as far as the deterministic approach is concerned, the total restoration times for DS1 to DS3 were obtained by adding the mode value of each triangular distribution and the upper values of each uniform distribution. For the stochastic analysis, and also for the deterministic analysis for DS4, a Monte Carlo simulation (10 5 samples) was employed to probabilistically model the restoration time of the repair works, using a normal distribution (Table 6). 
Table 6. Repair works and their duration for the three bridges

\begin{tabular}{|c|c|c|c|c|c|c|}
\hline \multirow{2}{*}{ DS } & \multirow{2}{*}{ Task ID } & \multirow{2}{*}{ Task description } & \multirow{2}{*}{ Distribution } & Bridge 1 & Bridge 2 & Bridge 3 \\
\hline & & & & \multicolumn{3}{|c|}{ Lower/Mode/Upper } \\
\hline \multirow{4}{*}{$D S 1$} & 1.1 & Repair minor spall & Triangular & $2 / 4 / 6$ & $2 / 4 / 6$ & $2 / 4 / 6$ \\
\hline & 1.2 & Repair cracks with epoxy & Triangular & $4 / 7 / 11$ & $4 / 7 / 11$ & $4 / 7 / 11$ \\
\hline & 1.3 & Realign the bearings & Uniform & $5 /-/ 10$ & $1 /-/ 5$ & $3 /-/ 8$ \\
\hline & 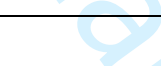 & Total mean restoration time & & 21 & 16 & 19 \\
\hline \multirow{15}{*}{$D S 2$} & 2.1 & Repair moderate spall & Triangular & $3 / 6 / 9$ & $3 / 6 / 9$ & $3 / 6 / 9$ \\
\hline & 2.2 & Repair cracks with epoxy & Triangular & $4 / 8 / 12$ & $4 / 8 / 12$ & $4 / 8 / 12$ \\
\hline & 2.3 & Realign bearings & Uniform & $5 /-/ 10$ & $1 /-/ 5$ & $3 /-/ 7$ \\
\hline & 2.4 & Replace expansion joint & Triangular & $4 / 7 / 10$ & $4 / 7 / 10$ & $4 / 6 / 8$ \\
\hline & 2.5 & Repair continuous slabs & Triangular & $1 / 2 / 4$ & - & - \\
\hline & 2.6 & Repair of backwalls & Triangular & $2 / 10 / 20$ & $2 / 10 / 20$ & $6 / 12 / 18$ \\
\hline & 2.7 & Repair box girder cracks & Triangular & - & $5 / 10 / 15$ & $5 / 10 / 15$ \\
\hline & 2.8 & Repair piers & Triangular & - & - & $5 / 10 / 15$ \\
\hline & \multicolumn{3}{|c|}{ Total mean restoration time } & 43 & 46 & 59 \\
\hline & 3.1 & Repair extensive spall & Triangular & $4 / 8 / 12$ & $4 / 8 / 12$ & $4 / 8 / 12$ \\
\hline & 3.2 & Repair cracks with epoxy & Triangular & $4 / 8 / 12$ & $4 / 8 / 12$ & $4 / 8 / 12$ \\
\hline & 3.3 & $\begin{array}{c}\text { Remove/construct new } \\
\text { bearing pedestals }\end{array}$ & Triangular & $1 / 2 / 3$ & $1 / 2 / 3$ & $1 / 2 / 3$ \\
\hline & 3.4 & Install new bearings & Uniform & $10 /-/ 20$ & $4 /-/ 8$ & $5 /-/ 10$ \\
\hline & 3.5 & Replace expansion joint & Triangular & $4 / 7 / 10$ & $4 / 7 / 10$ & $4 / 6 / 8$ \\
\hline & 3.6 & $\begin{array}{l}\text { Reconstruct continuous } \\
\text { slabs }\end{array}$ & Triangular & $4 / 6 / 8$ & - & - \\
\hline
\end{tabular}

$D S 3$

3.7 (backwall, backfill,
approach slabs, wing

Triangular

$9 / 18 / 30 \quad 9 / 18 / 30$

$9 / 18 / 30$ walls)

\begin{tabular}{cccccc}
\hline 3.8 & Repair bent caps & Triangular & $10 / 20 / 30$ & - & - \\
\hline 3.9 & Repair piers & Triangular & - & $5 / 10 / 15$ & $15 / 30 / 45$ \\
\hline 3.10 & Repair box girder & Triangular & - & $9 / 18 / 30$ & $9 / 18 / 30$ \\
\hline 3.11 & Repair foundation & Triangular & $15 / 30 / 45$ & $15 / 30 / 45$ & $15 / 30 / 45$ \\
\hline \multirow{2}{*}{ TS4 } & Total mean restoration time & & 119 & 109 & 130 \\
\hline \multirow{2}{*}{4.1} & \multirow{2}{*}{ Reconstruction of bridge } & \multirow{2}{*}{ Normal } & $\mu=1080$ & $\mu=720$ & $\mu=1080$ \\
& & & $\sigma=216$ & $\sigma=144$ & $\sigma=216$
\end{tabular}

Apart from the repair time shown in Table 6, an idle time at each DS was also considered based on 
314 for the owner to react and commence restoration works. The post-event functionality at each DS was 315 assumed to be $75 \%$ for DS1, 25\% for DS2, 10\% for DS3 and 0\% for DS4, as per FEMA (2009) as discussed 316 in the previous section. In Figure 6, both the linear deterministic and the Monte Carlo stochastic restoration 317 curves of the examined bridges are presented. For the Monte Carlo simulation, a cumulative normal 318 distribution was assumed. The mean, $\mu$, and standard deviation, $\sigma$, used for each DS of each bridge (Table 7) were calculated based on a statistic process as it is shown in Figure 5. It is noted that $\mu$ at DS4 was assumed as five times larger than $\mu$ at DS3, as well as $\sigma$ at DS4 was assumed equal to $35 \%$ of $\mu$ at the same DS.

322 In addition to the restoration curves at each DS, also the resilience curves are plotted for the two scenarios examined bridges as per Equation 5. For the deterministic analysis, these curves are plotted considering the post-event functionality, the idle and the repair time, weighted with the probability of occurrence of each DS. In the stochastic analysis, the resilience curves are based on the consideration of $\mu$ and $\sigma$, weighted with the probability of occurrence of each DS.

Table 7. Mean and standard deviation of restoration time normal distribution at each DS for the three

\begin{tabular}{cccc}
\hline DS & Bridge 1 (days) & Bridge 2 (days) & Bridge 3 (days) \\
\hline \multirow{2}{*}{1} & $\mu=18.8$ & $\mu=14.3$ & $\mu=16.8$ \\
\cline { 2 - 4 } & $\sigma=2.2$ & $\sigma=2.0$ & $\sigma=2.2$ \\
\hline \multirow{2}{*}{2} & $\mu=41.5$ & $\mu=44.7$ & $\mu=57$ \\
\cline { 2 - 4 } & $\sigma=4.7$ & $\sigma=5.0$ & $\sigma=4.5$ \\
\hline \multirow{2}{*}{3} & $\mu=114$ & $\mu=109$ & $\mu=129.5$ \\
\cline { 2 - 4 } & $\sigma=9.2$ & $\sigma=9.3$ & $\sigma=11$ \\
\hline \multirow{2}{*}{4} & $\mu=570$ & $\mu=545$ & $\mu=647.5$ \\
\cline { 2 - 4 } & $\sigma=199.5$ & $\sigma=190.8$ & $\sigma=226.6$ \\
\hline
\end{tabular}


Due to the fact that the idle time was the same for the three bridges and the restoration time was similar for each DS of the three examined bridges, the restoration diagrams for the two approaches (left and right column in Figure 7) are almost alike. However, the resilience curves (black dashed lines in Figure 6) are different for each bridge, as these are strongly dependent on the probability of occurrence of each DS. The Resilience indices were calculated based on Equation 6, and normalized with respect to the DS4 total restoration time of each bridge as it is shown in Table 8. It is noted that the DS4 restoration time as resulted by the Monte Carlo analysis is significantly longer than the corresponding one for the deterministic analysis. This is due to the fact that the deterministic linear approach is based merely on the mean value of the estimated duration of each restoration task, while on the other hand, the stochastic Monte Carlo approach takes into account the probability density function of each task. Therefore, Monte Carlo approach depends also on the cumulative function of the fitted to the restoration tasks normal distribution, as Figure 5 implies. For both the stochastic and deterministic approaches, it is observed that the Resilience index gradually reduces as the DS shifts from 1 to 4. Moreover, since the restoration time is similar for each DS for the three bridges examined, the Resilience indices are also similar for each DS. For both approaches, R values are similar in the case of DS1 to DS3, with slightly larger values observed in the stochastic approach. In the case of DS4, a dispersion of R values is observed between the two approaches (stochastic analysis having smaller values than the deterministic one). This is due to the fact that, as it has been already mentioned, Monte Carlo assigns significantly longer total restoration time. Hence, for this particular case study, the resilience is almost independent of the type of model of the restoration time (linear, stochastic) for DS1 DS3, while somehow worth mentioned deviations are observed in the case of DS4. 
The $\mathrm{R}$ values obtained by the resilience curves for the two scenarios vary between the three bridges as the damage probabilities affect the estimation of resilience indices. However, the deterministic and stochastic

Table 8. Resilience indices (R) of the examined bridges for each DS and seismic scenario, based on deterministic and stochastic analysis

\begin{tabular}{ccccccc}
\hline $\boldsymbol{R}$ & \multicolumn{2}{c}{ Bridge 1 } & \multicolumn{2}{c}{ Bridge 2 } & \multicolumn{2}{c}{ Bridge 3 } \\
\hline DS & Deterministic & Stochastic & Deterministic & Stochastic & Deterministic & Stochastic \\
\hline 1 & 0.995 & 0.993 & 0.995 & 0.994 & 0.995 & 0.993 \\
\hline 2 & 0.968 & 0.964 & 0.967 & 0.963 & 0.963 & 0.955 \\
\hline 3 & 0.922 & 0.903 & 0.925 & 0.907 & 0.918 & 0.892 \\
\hline 4 & 0.713 & 0.512 & 0.723 & 0.533 & 0.680 & 0.448 \\
\hline Scenario I & 0.997 & 0.994 & 0.914 & 0.852 & 0.964 & 0.946 \\
\hline Scenario II & 0.980 & 0.964 & 0.848 & 0.730 & 0.939 & 0.901 \\
\hline
\end{tabular}
approaches give similar estimations. Overall, Bridge 1 has the highest resilience index due to lower vulnerability, while $\mathrm{R}$ values, as expected, are lower for the more severe scenario (II). The variation of $\mathrm{R}$ values with the examined total restoration time for the four DSs is shown in Figure 7, where the difference between the two approaches is significant for DS4, again because of the longer restoration time that Monte Carlo analysis assigns. It is noted that the diagrams in Figure 7 should be read as functions that give different $\mathrm{R}$ values for different total restoration time and asymptotically approach the full functionality equal to $100 \%$. Therefore, for the cases examined in the present study, the $\mathrm{R}$ values correspond to the examined bridges' total restoration time should be taken into account, i.e. for all cases, the $\mathrm{R}$ values were calculated considering the same final time $\left(\mathrm{t}_{\mathrm{f}}\right)$ for both the linear and the Monte-Carlo models. The final time $\mathrm{t}_{\mathrm{f}}(\mathrm{i} . \mathrm{e}$. time horizon) was considered equal to1200 days, which is approximately 3 years. Observing Figure 7, it is noted that there is a significant discrepancy between the R values of DS4 for linear deterministic and stochastic Monte Carlo analysis. This is attributed to the fact that the first approach has a fixed value for the duration of the restoration tasks, whereas the stochastic simulation has large standard deviations, which are of increasing value for more severe DSs, e.g. DS4. 


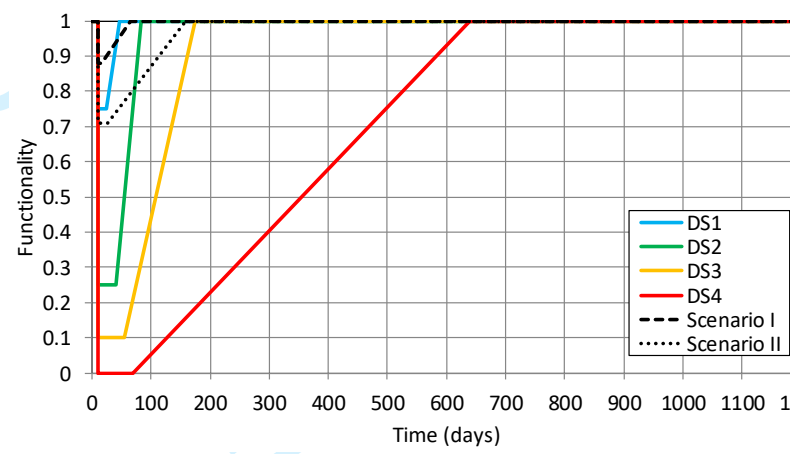

(a)

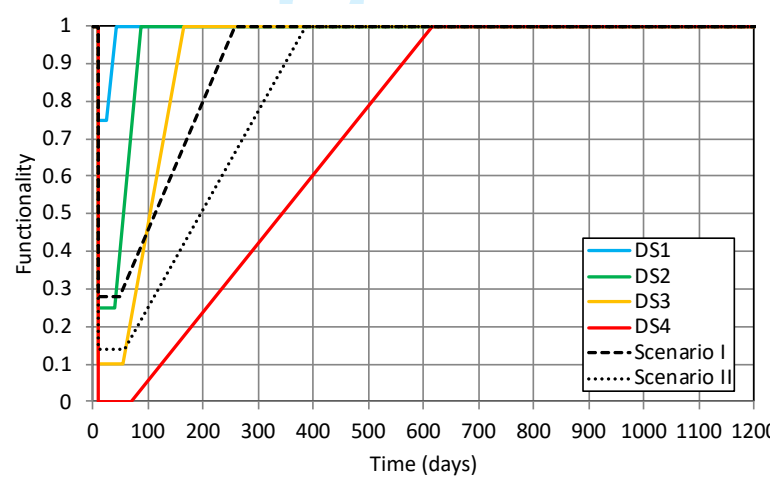

(c)

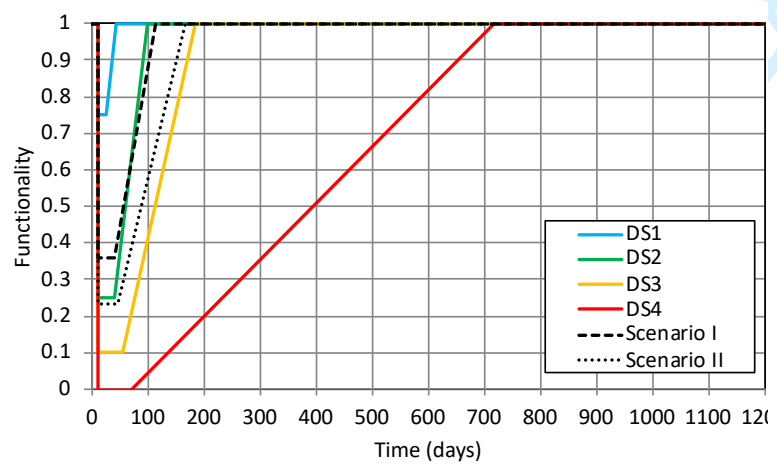

(e)

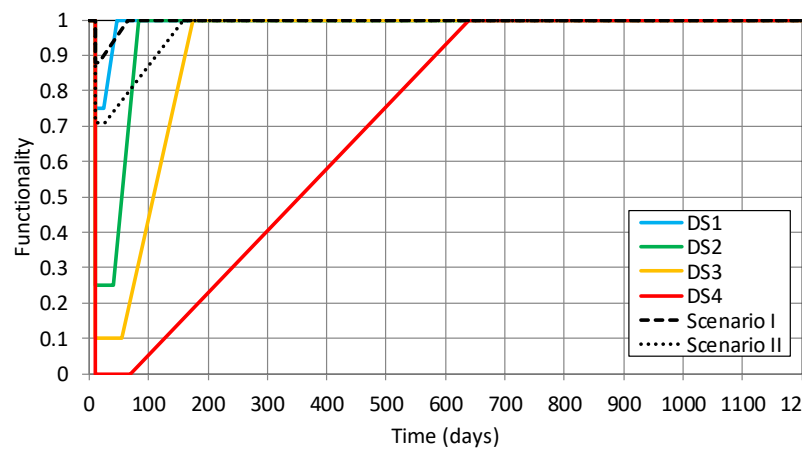

(b)

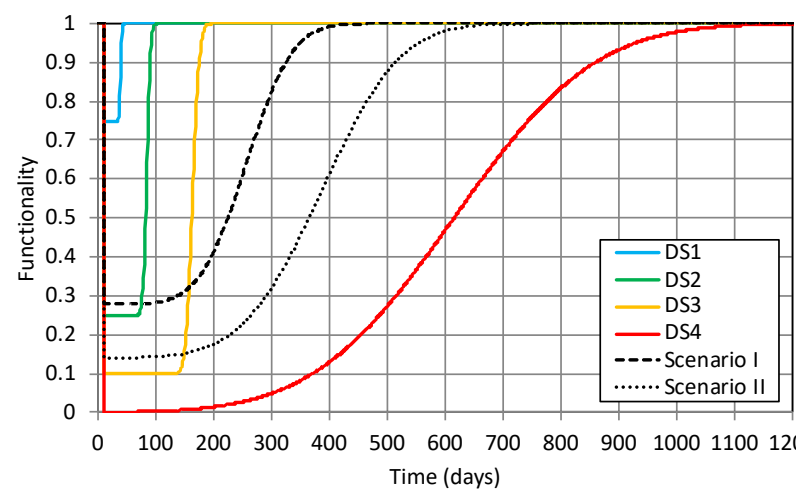

(d)

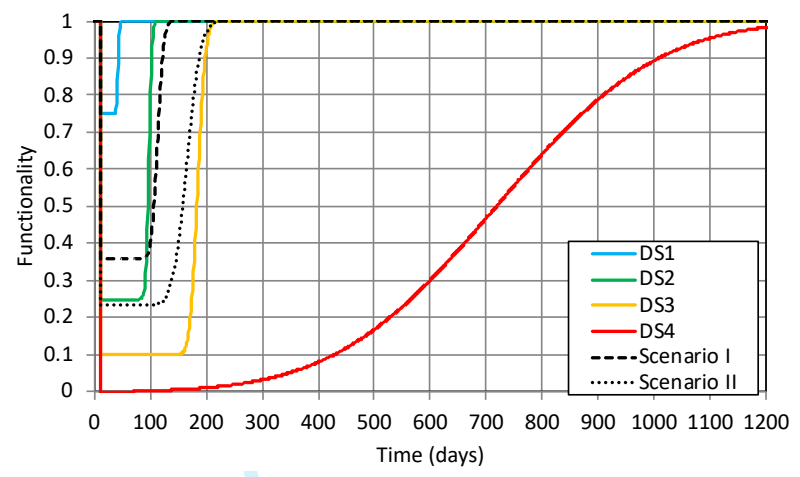

(f)

Figure 6. Deterministic linear (left column) and stochastic Monte Carlo (right column) restoration and resilience curves for: (a-b) Bridge1, (c-d) Bridge 2 and (e-f) Bridge 3 


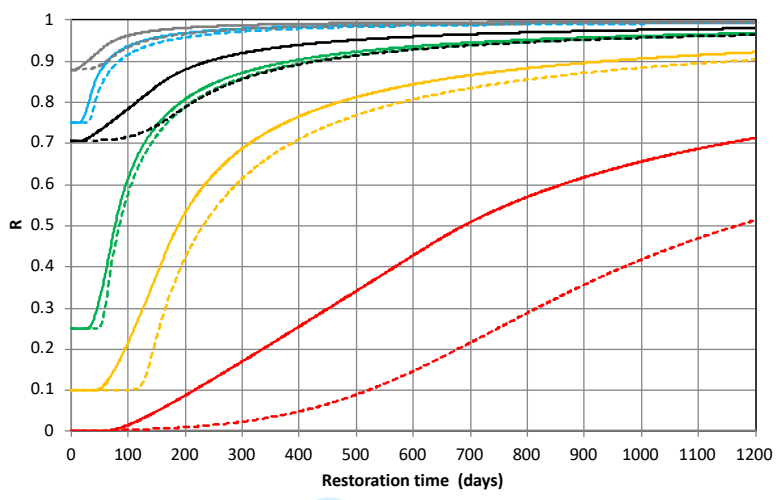

(a)

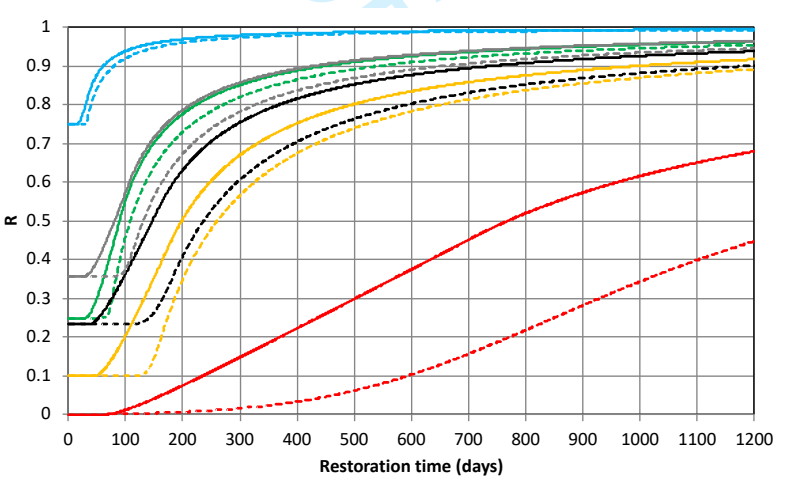

(c)

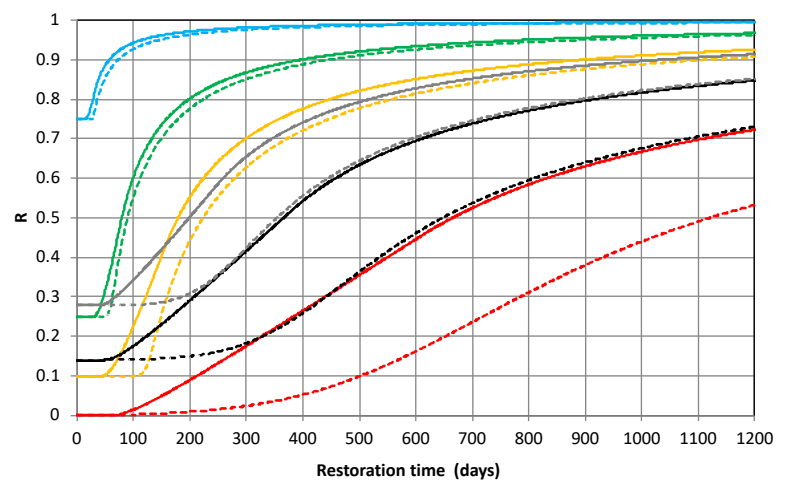

(b)

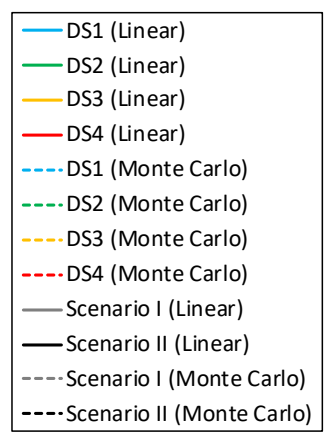

Figure 7. Temporal variation of resilience ratios for: (a) Bridge 1, (b) Bridge 2 and (c) Bridge 3 for linear deterministic and stochastic Monte Carlo analysis

\section{Cost-based resilience index}

The loss of resilience is a measure of the lost functionality (Q), which can be measured by the resilience of the perfectly resilient asset, $\mathrm{R}=1$, minus the resilience index as calculated by Equation 6, which is smaller than 1, due to the occurrence of the seismic events. However, the loss of functionality of a bridge might be related to structural (direct) losses or other obstructions, e.g. debris on the bridge due to an earthquaketriggered landslide, the latter not necessarily inducing any structural damage (direct losses). The loss of functionality of the bridge will also result in indirect losses, which are consequences of the loss of resilience (1-R), such as the losses due to detour of traffic or business interruption. As the loss in resilience is not a measure of the direct and indirect monetary losses, a new resilience index is introduced, $\mathrm{R}_{\mathrm{C}}$, which encapsulates socio-economic consequences (direct and indirect losses) in the resilience assessment. This paper only included three bridges as the critical assets of the transport network, and hence the $\mathrm{R}_{\mathrm{C}}$ is normalised with respect to the bridge that has the greatest indirect loss in the portfolio. A similar concept is also applicable for assessing the resilience of portfolios of transport assets within a network and interdependent networks.

In particular, a cost-based resilience index, $\mathrm{R}_{\mathrm{C}}$, is defined in Equation 7, which is essentially an adjustment of the streamlined resilience index R, given in Equation 6, accounting for the direct and indirect losses. 
where, $C_{D}$ and $C_{I N}$ correspond to the direct and indirect cost of the bridge and $\gamma$ is a factor that takes into account the socio-economic impact of the indirect cost on the network operation compared to the direct losses. The value of $\gamma$ is chosen by the stakeholders based on expert judgement, considering the socioeconomic impact of a bridge failure on the transportation infrastructure, on the basis of damage extent, daily traffic, or accessibility to critical facilities (Cimellaro, 2016). According to the authors, a rational range of $\gamma$ is between 0.05 and 0.15 (in the present study $\gamma$ was set equal to 0.15 ). $C_{I N, \max }$ is the maximum indirect cost estimated for the portfolio of bridges under study. Obviously, for a single bridge or for the bridge having the maximum indirect cost within the portfolio, $C_{I N}$ coincides with $C_{I N, \max }$ and, hence, the ratio of $C_{I N}$ to $C_{I N, \max }$ is equal to one.

Therefore, $\mathrm{R}_{\mathrm{C}}$ is the streamlined $\mathrm{R}$ index decreased by two factors. The first one is related to the socioeconomic importance of the indirect loss of the examined bridge compared to its direct one, while the second factor normalizes this indirect cost of the bridge in accordance with the maximum indirect cost of the examined portfolio. The $\mathrm{R}_{\mathrm{C}}$ values calculated in the present study are compared with the $\mathrm{R}$ values in Table 9, for the two seismic scenarios. It is observed that the higher impact of the indirect losses is estimated in the resilience of Bridge 2. This is also defined by the ratio of $R_{C}$ to $R$, which describes the importance of the indirect costs in the resilience of each asset, i.e. the lower the ratio the most critical is the asset in terms of indirect losses. In this context, $\mathrm{R}_{\mathrm{C}}$ may be utilized as an additional decision-making tool, reflecting the consequences of indirect losses for different hazard scenarios, providing an objective means to facilitate decision-making by the stakeholders and network operators for efficient allocation of resources.

Table 9. Cost-based resilience indices $\left(\mathrm{R}_{\mathrm{C}}\right)$ for the examined portfolio of bridges

\begin{tabular}{ccccccc}
\hline \multirow{2}{*}{ Bridge } & \multicolumn{3}{c}{ Scenario I } & \multicolumn{3}{c}{ Scenario II } \\
\cline { 2 - 7 } & $R$ & $R_{C}$ & $R_{C} / R$ & $R$ & $R_{C}$ & $R_{C} / R$ \\
\hline 1 & 0.997 & 0.965 & 0.968 & 0.980 & 0.916 & 0.935 \\
\hline 2 & 0.914 & 0.697 & 0.763 & 0.848 & 0.664 & 0.783 \\
\hline 3 & 0.964 & 0.939 & 0.974 & 0.939 & 0.831 & 0.885 \\
\hline
\end{tabular}

\section{Conclusions}

This paper studied the resilience of three representative road bridges on the basis of a framework that encompasses hazard, vulnerability and restoration analysis. The resilience was evaluated, in terms of direct and indirect losses and restoration times for two seismic scenarios. The duration of the repair tasks was adjusted considering realistic local construction practices. The new evidence that this paper provides is the evaluation of resilience based on two commonly accepted, but different approaches for the modelling of 
the restoration tasks. These approaches are a simplified deterministic linear model in which the post-disaster functionality, i.e. during the restoration process, is a linear equation of the time and a stochastic one, where the uncertainty is addressed with streamlined statistics methods. The results are compared in terms of the resulting resilience indexes. This study came up with the following conclusions. There are differences between the two approaches with the stochastic one believed to be the most accurate complete damage scenarios. This is attributed to the standard deviation considered in the stochastic approach, which is higher in more severe damage states, e.g. DS4. This means that linear models are adequately accurate for less severe damage states, e.g. DS1, DS2, DS3, which makes them appropriate for managing minor to moderate post-hazard damage. Systematically the linear model is less conservative than the Monte-Carlo approach as it overestimates the resilience index, R. Regarding the R values for different bridge types and locations, the curved in-plane bridge (Bridge 3) has the lowest resilience. This is reflected both by the vulnerability of the structure, which leads to higher loss of functionality, and time-consuming restoration actions also related to the difficulty in accessing the bridge, because this is an overpass of the busy ring road of the city, which makes any restoration tasks more challenging. The other two bridges have similar resilience. In regard to the impact of indirect losses to the resilience of the three bridges, Bridge 2 is most critical, followed by Bridge 1 and Bridge 3. This is due to the higher vulnerability of Bridge 2 and the longer detour length for this particular bridge.

The value of the proposed framework and application at the asset level is the encapsulation of the direct and indirect losses and recovery process in two indices, which can facilitate the efficient allocation of resources, planning and interventions by the owners, toward safer and more resilient transport infrastructure. Thus, it is essential for the owners to define, with the help of engineers, appropriate thresholds for the resilience indices to expedite the decision-making according to their needs and priorities. The proposed framework and indices is of particular interest for, but not limited to, controlled access motorways such as a ring road of a city or a high-speed road, where there are not many alternative routes. The application at a wider network scale should also incorporate other factors toward a well-informed resilience-based decision making, on the basis of network analysis, including post-earthquake traffic demand variation as well as economic, social and environmental consequences, due to physical damage and traffic diversions.

\section{References}

Almufti, I., \& Willford, M.R. (2013). Resilience-based Earthquake Design (REDi) Rating System, version 1.0. Arup. 4

Akiyama, M., Frangopol, D. M., Ishibashi, H. (2019). Toward life-cycle reliability-, risk-and resiliencebased design and assessment of bridges and bridge networks under independent and interacting hazards: emphasis on earthquake, tsunami and corrosion. Structure and Infrastructure Engineering, https://doi: 10.1080/15732479.2019.1604770. 
Ayyub, B.M., (2014). Systems resilience for multihazard environments: Definition, metrics, and valuation for decision making. Risk Analysis, 34(2), 340-355.

Argyroudis, S.A., Mitoulis, S.A., Hofer, L., Zanini, M.A., Tubaldi, E., Frangopol, D.M. (2020). Resilience assessment framework for critical infrastructure in a multi-hazard environment. Science of the Total Environment, 714, 136854.

Argyroudis, S., Mitoulis, S.A., Winter, M.G., \& Kaynia, A.M. (2019). Fragility of transport assets exposed to multiple hazards: State-of-the-art review toward infrastructural resilience. Reliability Engineering and System Safety, 191, 106567.

Banerjee, S., Vishwanath, B. S., \& Devendiran, D. K. (2019). Multihazard resilience of highway bridges and bridge networks: a review. Structure and Infrastructure Engineering, 15(12), 1694-1714.

Basoz, N., Kiremidjian, A., King, S., \& Law, K. (1999). Statistical analysis of bridge damage data from the 1994 Northridge, CA, Earthquake. Earthquake Spectra , 15 (1), 25-54.

Billah, A., \& Alam, M. (2015). Seismic fragility assessment of highway bridges: a state-of-the-art- review. Structure and Infrastrure Engineering, 11 (6), 804-832.

Bocchini, P., \& Frangopol, D. (2012a). Optimal resilience and cost based post-disaster intervention prioratization for bridges along a highway segment. Journal of Bridge Engineering , 17 (1), 117-129.

Bocchini, P., \& Frangopol, D.M. (2012b). Restoration of bridge networks after an earthquake: multi-criteria intervention optimization. Earthquake Spectra, 28(2), 427-455.

Bocchini, P., Decò, A., \& Frangopol, D. (2012). Probabilistic functionality recovery model for resilience analysis. In F. Biondini, \& D. Frangopol (Ed.), Bridge Maintenance, Safety, Management, Resilience and Sustainability. London. Taylor \& Francis Group.

Bruneau, M., Chang, S.E., Eguchi, R.T., Lee, G.C., O’Rourke, T.D., Reinhorn, A.M., Shinozuka, M., Tierney, K., Wallace, W.A., \& von Winterfeldt, D. (2003). A framework to quantitatively assess and enhance the seismic resilience of communities. Earthquake Spectra, 19(4), 733-752.

Chandrasekaran, S., \& Banerjee, S. (2016). Retrofit optimization for resilience enhancement of bridges under multihazard scenario. Journal of Structural Engineering, 142(8), C4015012. doi:10.1061/(ASCE)ST.1943-541X.0001396

Cimellaro, G., Reinhorn, A., \& Bruneau, M. (2010). Framework for Analytical Quantification of Disaster Resilience. Engineering Structures, 32, 3639-3649.

Cimellaro, G.P. (2016). Urban resilience for emergency response and recovery. Fundamental Concepts and Applications, Geotechnical, Geological and Earthquake Engineering, 41, Springer International Publishing, ISBN 978-3-319-30656-8.

Decò, A., Bocchini, P., \& Frangopol, D. (2013). A probabilistic approach for the prediction of seismic resilience of bridges. Earthquake Engineering \& Structural Dynamics , 42, 1469-1487.

Dong, Y., \& Frangopol, D. (2015). Risk and resilience assessment of bridges under mainshock and aftershocks incorporating uncertainties. Engineering Structures , 83, 198-208. 
Elms, D., McCahon, I. and Dewhirst, R. (2019). Improving infrastructure resilience. Civil Engineering and Environmental Systems, 36(1), pp.83-99.

Elnashai, A., Borzi, B., \& Vlachos, S. (2004). Deformation-based vulnerability functions for RC bridges. Structural Engineering Mechanics, 17 (2), 215-244.

FEMA (2009). HAZUS - MH 2.1 Earthquake model technical manual. Washington, D.C.: Department of Homeland Security, Mitigation Division.

Gidaris, I., Padjett, J., Barbosa, A., Chen, S., Cox, D., Webb, B., \& Cerato, A. (2017). Multiple-hazard fragility and restoration models of highway bridges for regional risk and resilience assessment in the United States: state-of-the-art review. Journal of Structural Eingineering, 143 (3).

Hayat, E., Haigh, R., \& Amaratunga, D. (2019). A framework for reconstruction of road infrastructure after a disaster. International journal of disaster resilience in the built environment.

Karamlou, A., \& Bocchini, P. (2017). From component damage to system-level probabilistic restoration functions for a damaged bridge. Journal of Infrastructure Systems, 23 (3).

Komendantova, N., Scolobig, A., Garcia-Aristizabal, A., Monfort, D., \& Fleming, K. (2016). Multi-risk approach and urban resilience. International Journal of Disaster Resilience in the Built Environment.

Mackie, K., \& Stojadinovic, B. (2006). Post-earthquake functionality of highway overpass bridge. Earthquake Engineering and Structural Dynamics , 35, 77-93.

Moschonas, I., Kappos, A., Panetsos, P., Papadopoulos, V., Makarios, T., \& Thanopoulos, P. (2009). Seismic fragility curves for greek bridges: methodology and case studies. Bulletin of Earthquake Engineering , 7 (2), pp. 439-468.

Nakanishi, H., Black, J., \& Matsuo, K. (2014). Disaster resilience in transportation: Japan earthquake and tsunami 2011. International Journal of Disaster Resilience in the Built Environment.

Padgett, J., \& DesRoches, R. (2007). Bridge functionality relationships for improved seismic risk assessment of transportation networks. Earthquake Spectra , 23(1), 115-130.

Pitilakis, K., Riga, E., \& Anastasiadis, A. (2013). New code site classification, amplification factors and normalized response spectra based on a worldwide ground-motion database. Bulletin of Earthquake Engineering , 11 (4), 925-966.

Rehak, D., Senovsky, P., Hromada, M., \& Lovecek, T. (2019). Complex approach to assessing resilience of critical infrastructure elements. International Journal of Critical Infrastructure Protection, 25, 125138.

Sgambi, L., Garavaglia, E., Basso, N., \& Bontempi, F. (2014). Monte carlo simulation for seismic analysis of a long span suspension bridge. Engineering Structures, 78, 100-111.

Sharma, N., Tabandeh, A., \& Gardoni, P. (2018). Resilience analysis: A mathematical formulation to model resilience of engineering systems. Sustainable and Resilient Infrastructure, 3(2), 49-67. doi:10.1080/23789689.2017.1345257

Stefanidou S.P., \& Kappos A. J. (2018). Bridge-specific fragility analysis: when is it really necessary?. Bulletin of Earthquake Engineering, 1-36, https://doi.org/10.1007/s10518-018-00525-9. 
Twumasi-Boakye, R., \& Sobanjo, J. O. (2018). Resilience of regional transportation networks subjected to hazard-induced bridge damages. Journal of Transportation Engineering, Part A: Systems, 144(10), 04018062.

Venkittaraman, A., \& Banerjee, S. (2014). Enhancing resilience of highway bridges through seismic retrofit. Earthquake Engineering Structural Dynamics, 43, 1173-1191.

Werner, S., Taylor ,C., Cho ,S., Lavoie, J., Huyck, C., Eitzel, C., et al. (2006). REDARS 2 Methodology and software for seismiv risk analysis of highway systems. Buffalo, New York, United States: (MCEER06-SP08).

Woessner, J., Danciu, L., Giardini, D., Crowley, H., Cotton, F., Grunthal, G., Valensise, G., Arvidsson, R., Basili, R., Demircioglu, M., Hiemar, S., Meletti, C., Musson, R., Rovida, A., Sesetyan, K., \& Stucchi, M. (2015) The 2013 European seismic hazard model: key components and results. Bulleting of Earthquake Engineering, 13(12), 3553-3596. DOI 10.1007/s10518- 015-9795-1

Zhang, W., Wang, N., \& Nicholson, C. (2017). Resilience-based post-disaster recovery strategies for roadbridge networks. Structure and Infrastructure Engineering, 13(11), 1404-1413. 